\title{
Study on Strength and Stiffness of Meranti Wood Truss with Plywood Gusset Plate Connection and Lag Screw Fastener
}

\author{
Naomi Pratiwi \\ Civil Engineering Study Program, Faculty of Engineering, Parahyangan Catholic University, Bandung, INDONESIA \\ naomi.pratiwi@unpar.ac.id \\ Johannes Adhijoso Tjondro \\ Civil Engineering Study Program, Faculty of Engineering, Parahyangan Catholic University, Bandung, INDONESIA \\ tjondro@unpar.ac.id
}

\begin{abstract}
Wooden truss could be one of the options to be used as structural element in both building and bridge. Wooden truss overcomes the limitation of timber with great dimension with necessary strength. In this study, the wooden truss was designed with Meranti wood type with elasticity modulus of $10,520 \mathrm{MPa}$ and specific gravity of 0.8 . The timber used has cross-section size of $45 \mathrm{~mm} \times 45 \mathrm{~mm}$, with truss frame span of 2,445mm and height of $400 \mathrm{~mm}$. The connection between the timbers was using $18 \mathrm{~mm}$ thick plywood with $6 \mathrm{~mm}$ lag screw fastener. The destructive testing that was conducted on 3 test samples showed a result that the strength of the truss was at an ultimate load of 31,042 N with a ductility ratio of 5.61. Numerical study of the truss' stiffness with this connection model resulted in stiffness degree value of 0.94 .
\end{abstract}

Keywords: wooden truss, lag screw, plywood gusset plate, ultimate load, stiffness degree

\section{INTRODUCTION}

These days, application of environmentally-friendly building materials is being reintroduced in order to reduce other building materials that affect the environment, such as concrete that creates the greenhouse gas emissions. Indonesia as a developing country that is continuously building needs to return to nature as the source for construction material, which is wood. Indonesia has a diversity of wood species that grow in nature and could be used to support the infrastructure development such as simple building and bridges.

However, availability of wood with large dimension and necessary strength is also limited. Therefore, truss becomes one of the solutions to overcome this limitation. Truss could be shaped with various connection types. Plywood gusset plate and lag screw fastener are one of connection type that is easy to work at and with sufficient materials available (Williamson, 2002; Shan, 1990).

This study was conducted to delve deeper into the trait of the floor supporting truss with the aforementioned connection model. Destructive testing was conducted to find out the strength and stiffness of Meranti Wood truss. A numerical study was then performed to obtain the stiffness degree value from truss with aforesaid connection type.

\section{EXPERIMENT DETAIL}

\subsection{Preparation of Wooden Truss Element}

The wood type used was Red Meranti (Shorea $s p$.). The physical and mechanical traits of the timber were tested based on ASTM D2395-02 (American Society for Testing and Materials, 2008). The Meranti wood used has elasticity modulus of $10,520 \mathrm{MPa}$ and ovendry specific gravity of 0.8 with a moisture content of $14 \%$. This test result showed that the timber used was included on wood type with E10 quality code, as stated in the SNI 7933-2013 (Standar Nasional Indonesia, 2013).

The truss on the test sample has frame span of 2,445 $\mathrm{mm}$ with a height of $400 \mathrm{~mm}$. The horizontal, vertical, and diagonal truss elements all have the same crosssection which was square with $45 \mathrm{~mm}$ of size. The scheme and dimension of the test sample are shown in Figure 1 and Figure 2.

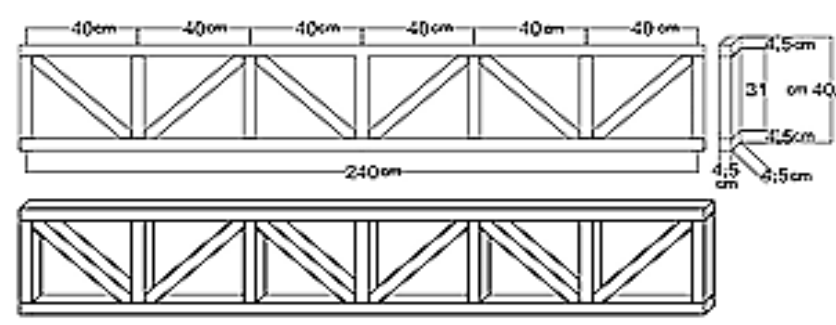

Figure 1. Scheme of wooden truss 


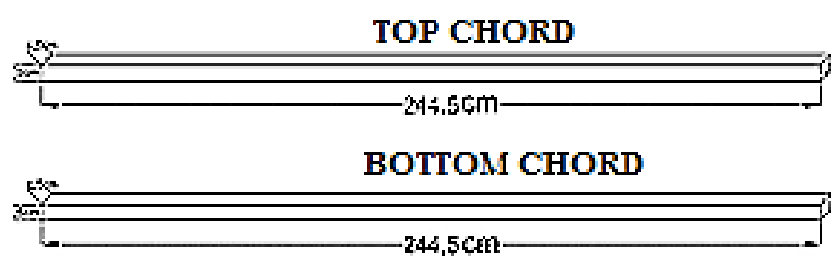

VERTICAL MEMBER DLAGONAL MEMBER
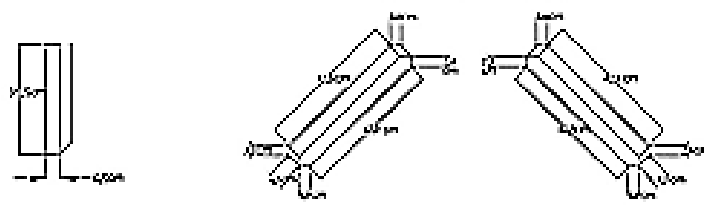

Figure 2. Element dimension of truss

\subsection{Connection}

Lag screw with $6 \mathrm{~mm}$ diameter and $4 \mathrm{~mm}$ length was used as fastener between the trusses using the gusset plate made from plywood. Shear strength test of the lag screw showed the maximum shear strength of $4,171.3 \mathrm{~N}$. While the plywood used as the connection plate has a moisture content of $11 \%$ with a specific gravity of $0.35 \mathrm{gr} / \mathrm{cm}^{3}$. The screw requirement was calculated based on the axial force that occurred on each timber based on a result obtained from modeling of the wooden truss with a weighting of $0.18 \mathrm{kN} / \mathrm{m}^{2}$ (additional dead load in the form of the floor of $3 \mathrm{~mm}$ thick wood plate), and $1.92 \mathrm{kN} / \mathrm{m}^{2}$ (live load).

Table 1 shows the reference design value of fastener that undergone lateral force, or on the SNI 7973-2013 (SNI, 2013) also called yield limit equation. The one that was used was the single shear value. Based on the calculation, the capacity of one lag screw was $622 \mathrm{~N}$ which was on mode 2 of failure modes on the connection. Figure 3 shows three test samples that were ready to be used for destructive testing.

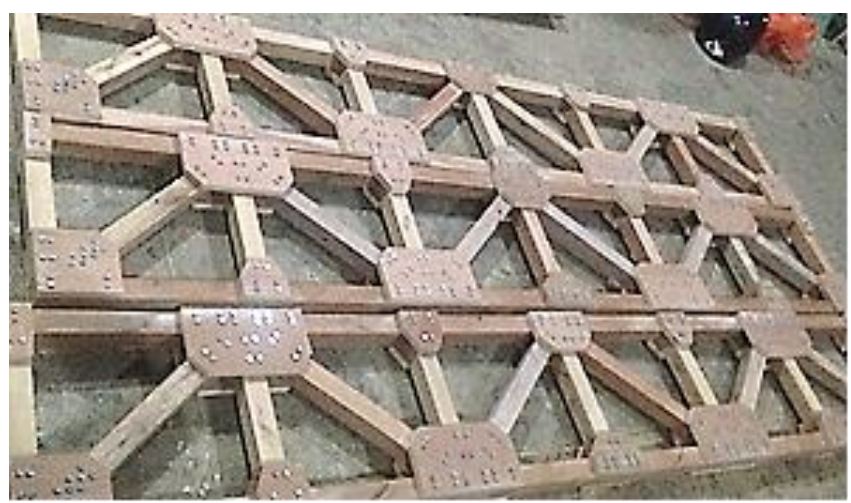

Figure 3. Wooden truss test samples
Table 1. Yield Limit Equation - Single Shear

\begin{tabular}{|c|c|}
\hline Yield Mode & Single Shear \\
\hline $\mathrm{I}_{\mathrm{m}}$ & $Z=\frac{D \cdot l_{m} \cdot F_{e m}}{R_{d}}$ \\
\hline $\mathrm{I}_{\mathrm{s}}$ & $Z=\frac{D \cdot l_{s} \cdot F_{e s}}{R_{d}}$ \\
\hline II & $Z=\frac{k_{1} \cdot D \cdot l_{s} F_{e s}}{R_{d}}$ \\
\hline $\mathrm{III}_{\mathrm{m}}$ & $Z=\frac{k_{2} \cdot D \cdot l_{s} F_{e m}}{\left(1+2 R_{e}\right) R_{d}}$ \\
\hline $\mathrm{III}_{\mathrm{s}}$ & $Z=\frac{k_{3} \cdot D \cdot l_{s} F_{e m}}{\left(2+R_{e}\right) R_{d}}$ \\
\hline IV & $Z=\frac{D^{2}}{R_{d}} \sqrt{\frac{2 F_{e m} F_{y b}}{3\left(1+R_{e}\right)}}$ \\
\hline \multicolumn{2}{|l|}{ Note } \\
\hline$k_{1}=\underline{\sqrt{R_{e}+}}$ & 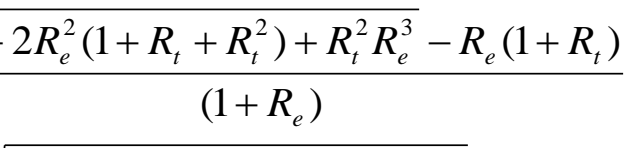 \\
\hline$k_{2}=-1+$ & $2\left(1+R_{e}\right)+\frac{2 F_{y b}\left(1+2 R_{e}\right) D^{2}}{3 F_{e m} l_{m}^{2}}$ \\
\hline$k_{3}=-1+$ & $\sqrt{\frac{2\left(1+R_{e}\right)}{R_{e}}+\frac{2 F_{y b}\left(2+R_{e}\right) D^{2}}{3 F_{e m} l_{s}^{2}}}$ \\
\hline
\end{tabular}

whereas $D$ is screw diameter $=6 \mathrm{~mm} ; F y b$ is bending yield strength of the dowel $=483 \mathrm{MPa} ; R d$ is reduction requirement taken as $0.4 D+0.5=2.9$ for $D \leq 6.35 \mathrm{~mm} ;$ Re is Fem/Fes $=\frac{56}{25.9}=2.162 ; F_{\text {em }}$ is strength of the dowel bearing on the main structure component $=56 \mathrm{MPa} ; F_{e s}$ is the strength of dowel bearing on the side structure component $=25.9 \mathrm{MPa}$.

$R t$ is $\ell m / \ell_{s}=\frac{20}{18}=1.11 ; \ell m$ is the length of dowel bearing on the main structure component $(20 \mathrm{~mm}) ; \boldsymbol{\ell} \boldsymbol{s}$ is the length of wedge bearing on the side structure component $(18 \mathrm{~mm})$. Figure 4 shows the connection scheme of truss for each joint.

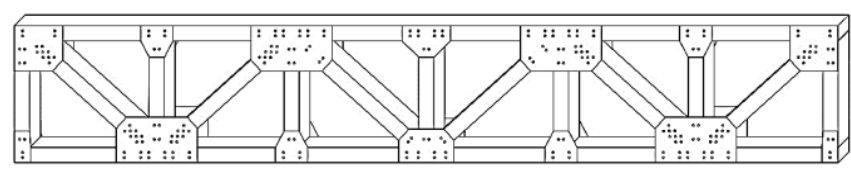

Figure 4. Connection scheme of truss

\subsection{Destructive testing}

Destructive testing was conducted using the UTM (Universal Testing Machine). The purpose of this test was to obtain the strength of the wooden truss (Sagara, et al., 2017). The three truss frames were tested by loading weight on 2 points on a third of the 
span, and the deflection occurred up to the maximum load that could be borne (Figure 5). The adding load speed that was applied was equal to $6 \mathrm{~mm} / \mathrm{min}$.

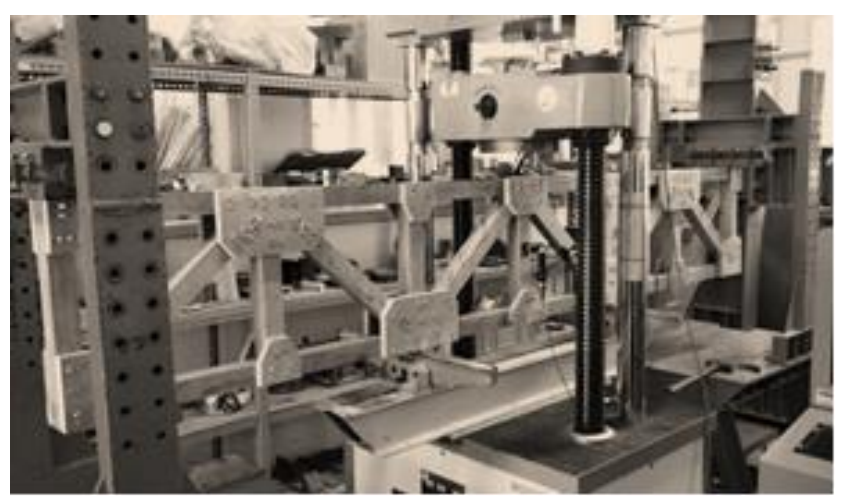

Figure 5. Destructive testing of the truss models

\subsection{Experimental Result}

Figure 6 to Figure 8 show the graphic on the relation between load and deflection for three of the test samples, which was obtained from the destructive testing result. Design load, proportional load, and ultimate load, also the deflection occurred are shown on each graph.

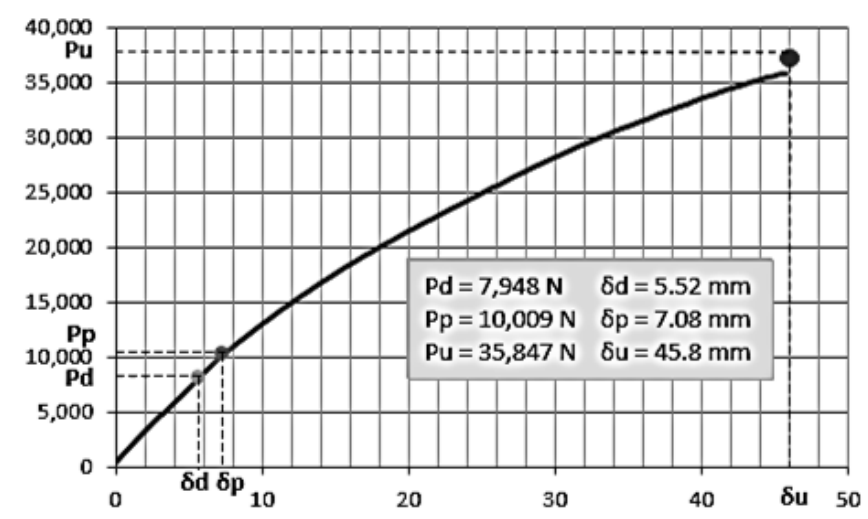

Figure 6. Graphic of load - deflection of Truss - 1

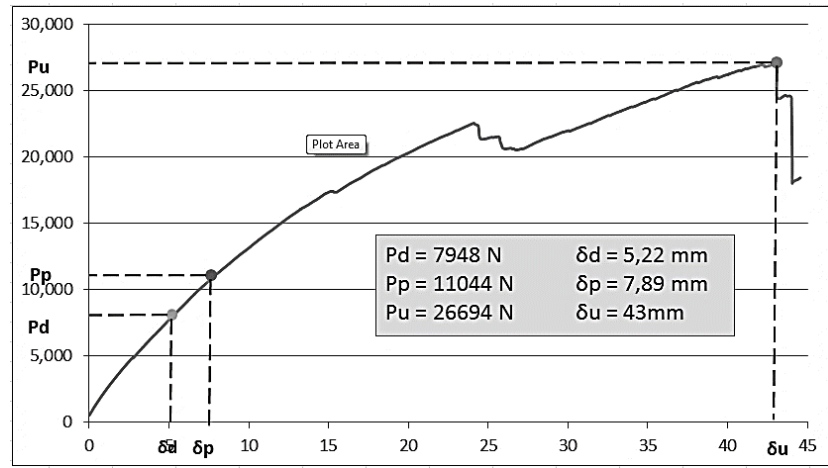

Figure 7. Graphic of load - deflection of Truss -2

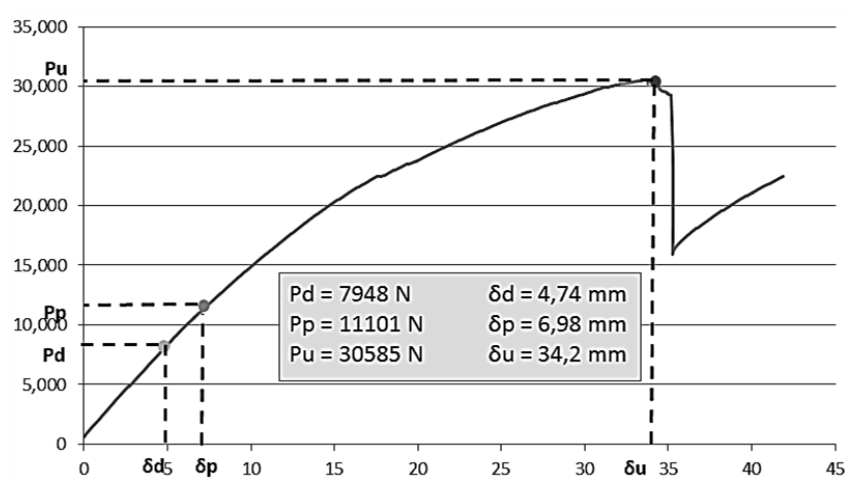

Figure 8. Graphic of load - deflection of Truss -3

\section{NUMERICAL MODEL}

A numerical model was made to obtain stiffness value of the truss, and to conduct validation of the occurred deflection value that occurred in the experiment with the deflection resulted from the mode. The numeric model was made with help from the SAP2000 program. The values of material properties, such as elasticity modulus and specific gravity, were taken from the testing that has been carried out at the beginning of the experiment. The truss model was given a centralized load on the third-point in the amount of proportional load.

There were 3 types of stiffness value that were modeled. The first truss model was made with the assumption that every connection is pinned connection. The second truss model was made with the assumption that every connection was rigid connection/continuous. While the third truss model was made by using fixity partial, in which it is assuming that connection on each member of the truss has connection type between pinned connection and rigid connection.

The value of connection stiffness was calculated by Romstad and Subramanian as shown in Equation (1) (Romstad \& Subramanian, 1970)

$S_{c}=\frac{\lambda 4 E I}{L}$

whereas $S_{c}$ is connection stiffness value and $\lambda$ is partial fixity value of the connection. For rigid connection, $\lambda$ value is 1 . This means that the truss has the stiffness to defend the original angle between every member of the truss. As for the pinned connection, the $\lambda$ value is 0 . For the semi-rigid connection, the $\lambda$ value is $0<\lambda<1$. Therefore, the calculation was $S_{c}$ value for $\lambda=0.1 ; 0.2 ; 0.3$; etc. up to $\lambda=0.9$.

Figure 9 shows the SAP 2000 model that used partial fixity to the model connection between the members of the truss. 


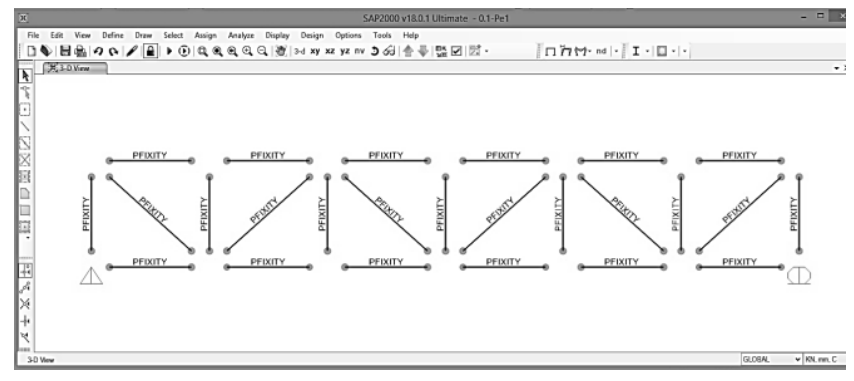

Figure 9. Truss model with partial fixity

The result of the model with $0<\lambda<1$ value for each proportional weighting, $P p_{1}, P p_{2}$, and $P p_{3}$, are shown in Table 2.

Table 2. Deflection from SAP2000 model analysis results

\begin{tabular}{llll}
\hline$\lambda$ & $P p_{1}$ & $P p_{2}$ & $P p_{3}$ \\
& $10.01 \mathrm{kN}$ & $11.044 \mathrm{kN}$ & $11.101 \mathrm{kN}$ \\
\hline & $\delta 1(\mathrm{~mm})$ & $\delta 2(\mathrm{~mm})$ & $\delta 3(\mathrm{~mm})$ \\
\hline 1 (rigid) & 6.99 & 7.82 & 6.91 \\
0.9 & 7.11 & 7.95 & 7.03 \\
0.8 & 7.11 & 7.95 & 7.03 \\
0.7 & 7.11 & 7.96 & 7.04 \\
0.6 & 7.11 & 7.96 & 7.04 \\
0.5 & 7.11 & 7.96 & 7.04 \\
0.4 & 7.12 & 7.97 & 7.05 \\
0.3 & 7.12 & 7.97 & 7.05 \\
0.2 & 7.13 & 7.98 & 7.05 \\
0.1 & 7.13 & 7.98 & 7.06 \\
0 (pinned) & 7.14 & 7.98 & 7.06 \\
\hline
\end{tabular}

\section{RESULT AND DISCUSSION}

\subsection{Ductility}

The result from destructive testing is shown in Table 3 . Pe and $\delta$ e are load and deflection at elastic limit whereas $\mathrm{Pu}$ and $\delta \mathrm{u}$ are load and deflection at the ultimate limit.

Table 3. Result of destructive testing on test sample truss

\begin{tabular}{lllll}
\hline \multirow{2}{*}{ No } & $\mathrm{Pe}$ & $\delta \mathrm{e}$ & $\mathrm{Pu}$ & $\delta \mathrm{u}$ \\
\cline { 2 - 5 } & $(\mathrm{N})$ & $(\mathrm{mm})$ & $(\mathrm{N})$ & $(\mathrm{mm})$ \\
\hline 1 & 10,009 & 7.08 & 35,847 & 45.9 \\
2 & 11,044 & 7.89 & 26,694 & 43.0 \\
3 & 11,101 & 6.98 & 30,585 & 34.2 \\
\hline
\end{tabular}

The result of destructive testing was then used to calculate ductility, which is a comparison between the deflections that occurred on ultimate condition to the proportional ductility (Stalnaker \& Harris, 1997). It then resulted in the mean ductility of 5.61 for a truss with this connection type. The results are shown in Table 4.
Table 4. Calculation on truss ductility

\begin{tabular}{lll}
\hline No & $\begin{array}{l}\text { Ultimate displacement } \\
\text { ductility }\end{array}$ & $\begin{array}{l}\text { Mean } \\
\text { ductility }\end{array}$ \\
\hline 1 & 6.48 & \\
2 & 5.45 & 5.61 \\
3 & 4.90 & \\
\hline
\end{tabular}

\subsection{Stiffness Degree}

From the result of the numerical analysis, it was obtained that Truss -1 with $P_{p}=10,009 \mathrm{~N}$ and $\delta_{\mathrm{p}}$ of $7.08 \mathrm{~mm}$ on destructive testing, with partial fixity value $\lambda=0.93$, as shown by the model. For Truss -2 with $P_{p}=11,044 \mathrm{~N}$ and $\delta_{\mathrm{p}}=7.89 \mathrm{~mm}$, the partial fixity value $\lambda=0.95$, as shown by the model. While the Truss -3 with $P_{p}=11,101 \mathrm{~N}$ and $\delta_{\mathrm{p}}=6.98 \mathrm{~mm}$, the value of partial fixity was $\lambda=0.95$, as shown by the model. The graph of deflection of truss can be seen on Figure 10 to Figure 12.

Therefore, the mean partial fixity value for the three test samples was 0.94 .

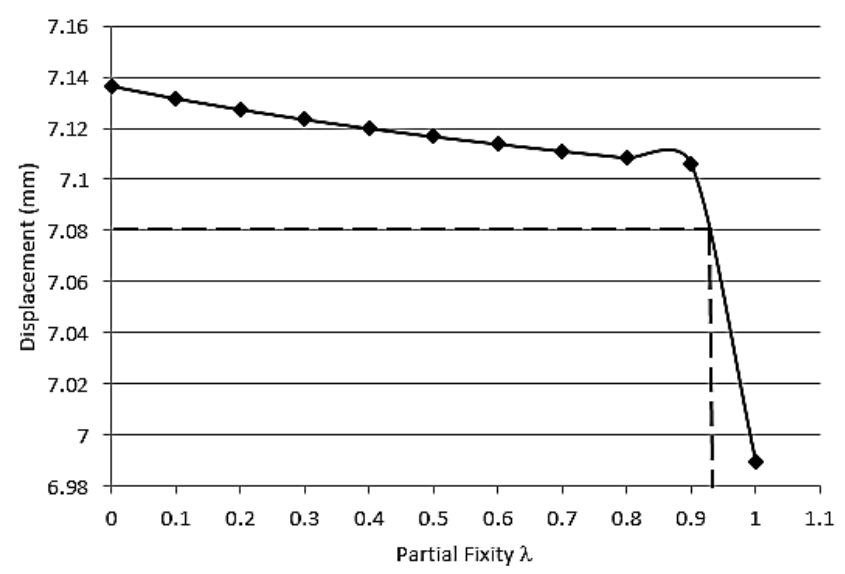

Figure 10. Deflection of truss -1 model

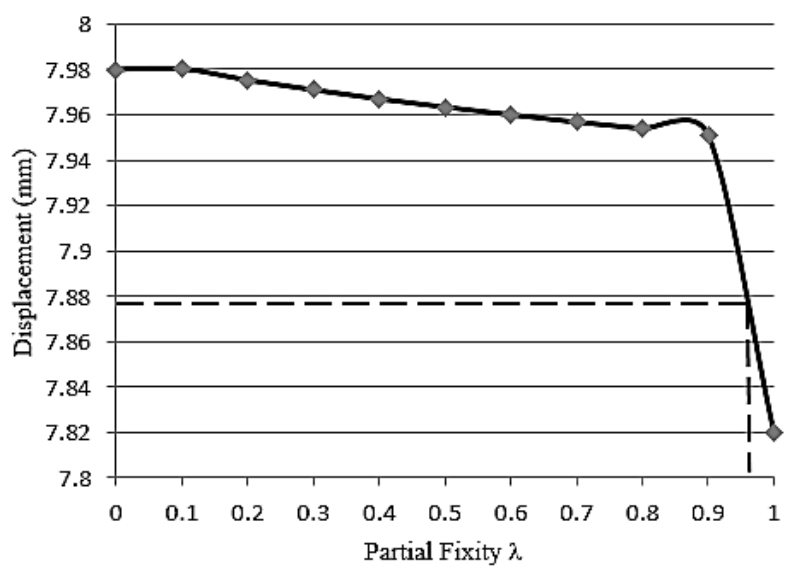

Figure 11. Deflection of truss -2 model 


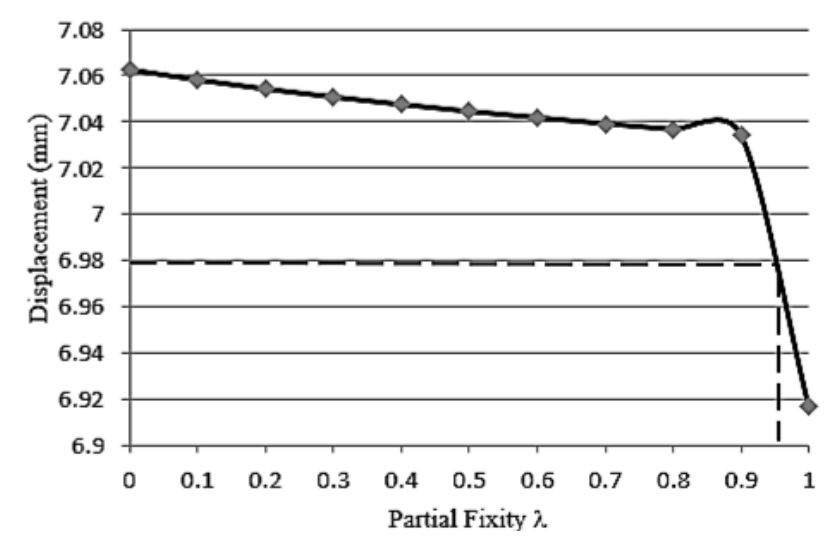

Figure 12. Deflection of truss -3 model

\subsection{Failure Modes on Wooden Truss Testing}

On ultimate condition, Wooden Truss 1 and 3 have similar failure modes, which were on the first diagonal log, in which it was already known that it has the largest internal forces in the form of tensile strength. The occurred failure was ductile, is characterized by the crack that formed slowly before the log finally failed (Aghayere, 2007).

In test sample 2 and 3 , the horizontal log also suffered from failure, due to the existence of knot, which then caused strength reduction in the wood. This became important when the wooden material is used as a structural element, in which it should be selectively chosen to avoid using defective wood which they could reduce the strength capacity of the wood.

Failure did not occur in the connection area because the shear stress from the lag screw combination on each connection points had not passed the maximum value. Location and typical failure modes are shown from Figure 13 to Figure 19.

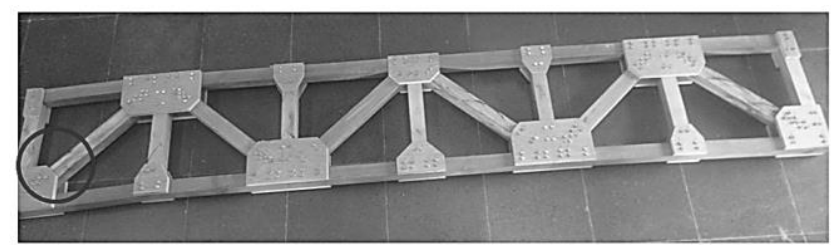

Figure 13. Failure location of Truss 1

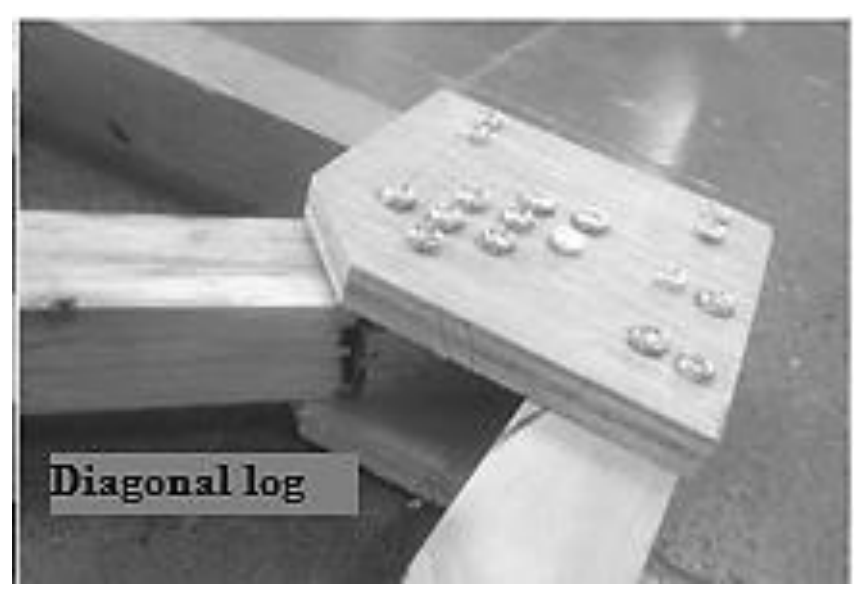

Figure 14. Failure on diagonal log of Truss 1 caused by tensile strength

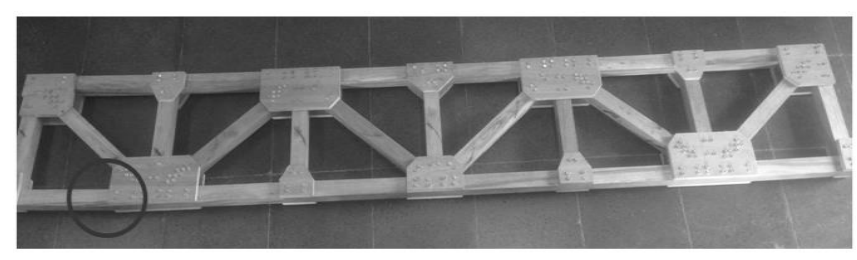

Figure 15. Failure location of Truss 2

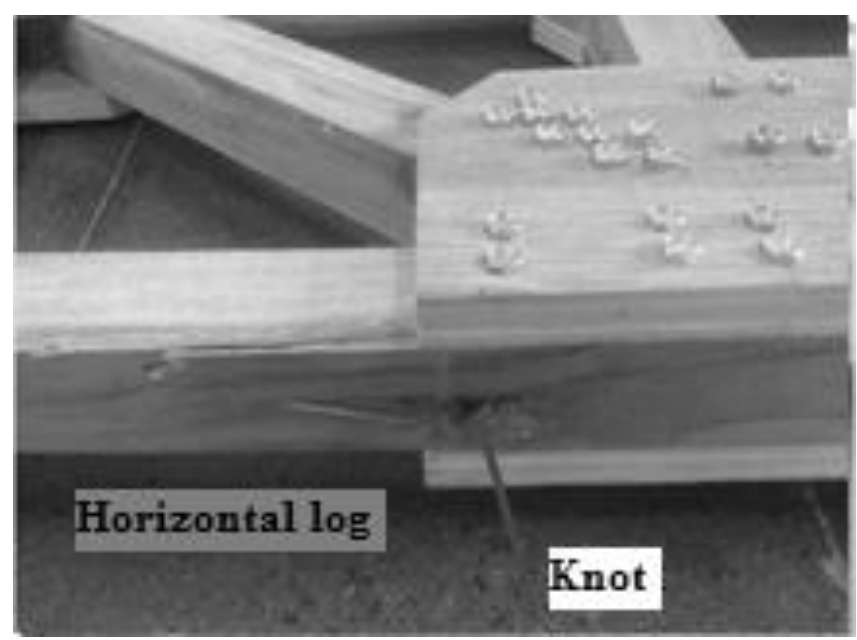

Figure 16. Failure on horizontal log of Truss 2 caused by presence of knot

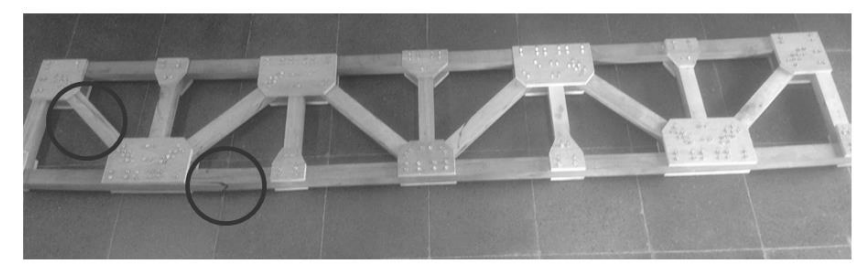

Figure 17. Failure location of Truss 3 


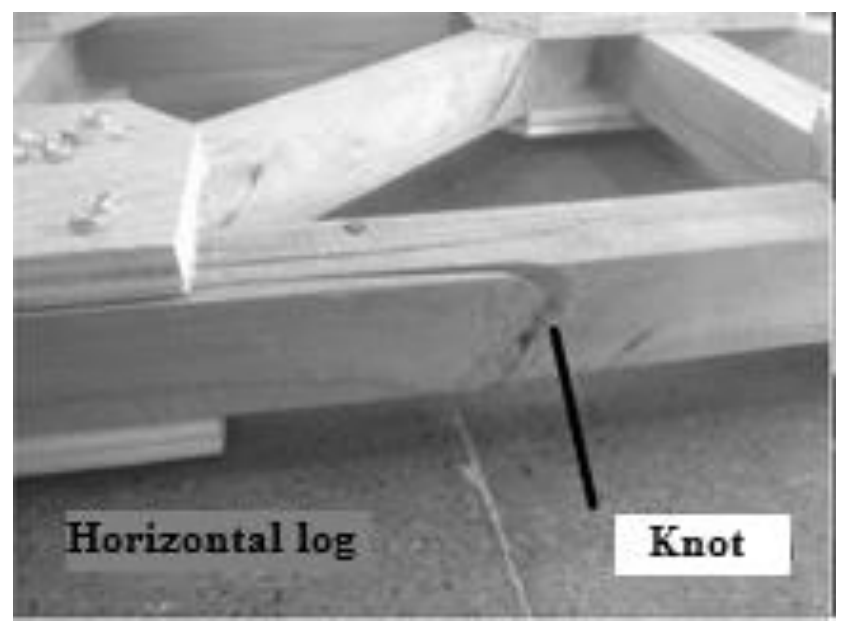

Figure 18. Failure of Truss 3 on its horizontal log caused by presence of knot

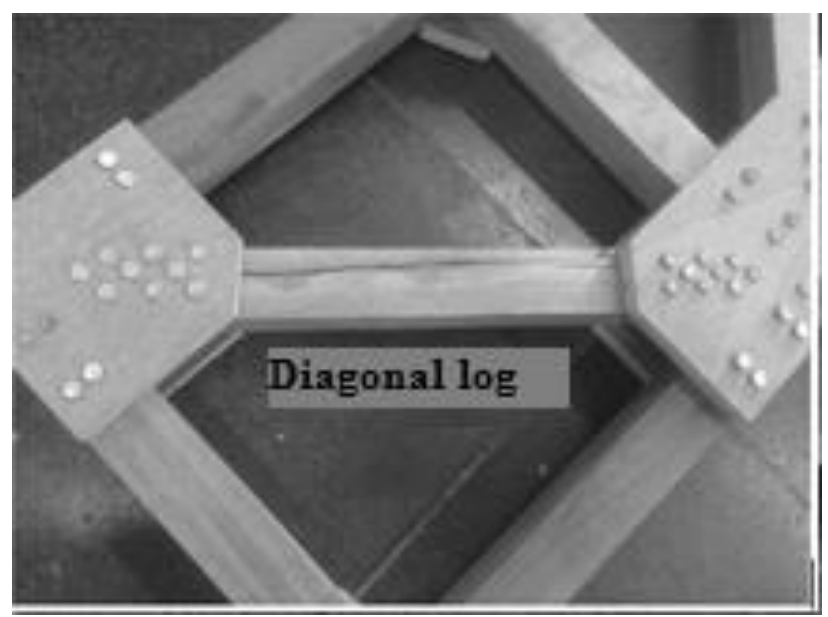

Figure 19. Failure on Truss 3 on its diagonal log caused by tensile strength

\section{CONCLUSIONS}

Wooden truss with plywood gusset plate connection and lag screw fastener that was used as floor supporting truss has an adequate safety factor, which was 1.35 in proportional condition, and 3.91 on ultimate condition. Wooden truss has stiffness on the connection that located between the pure pinned connection and pure rigid connection. The numerical model showed that the stiffness degree value (partial fixity) from three of the truss test samples was of 0.94 . The ductility value from the displacement of this connection was of 5.61 .

\section{REFERENCES}

Aghayere, A., 2007. Structural Wood Design A Practice-Oriented Approach Using the ASD Method. 1 ed. Hoboken, New Jersey: John Willey and Sons.

American Society for Testing and Materials, 2008. ASTM D2395-02: Standard Methods of Specific Gravity of Wood and Wood-Based Materials. Annual Book of ASTM Standards volume 04.10 ed. Baltimore: American Society for Testing and Materials;.

Romstad \& Subramanian, 1970. Non-Linier Static and Cyclic Analysis of Steel Frames With Semi-Rigid Connection. Oxford: Elsevier Ltd.

Sagara, A., Tjondro, J. A. \& Shiddiq, H. A., 2017. Experimental study on strength and stiffness connection of wooden truss structure. Palembang, EDP Sciences, MATEC Web of Conferences.

Somayaji, S., 1990. Structural Wood Design. 1 ed. St. Paul: West Publishing Company.

Stalnaker, J. J. \& Harris, E. C., 1997. Structural Design in Wood. 2 ed. New York: Chapman \& Hall.

Standar Nasional Indonesia, 2013. Spesifikasi Desain untuk Konstruksi Kayu. SNI 7973:2013 ed. Jakarta: Badan Standar Indonesia.

Williamson, T. G., 2002. APA Engineered Wood Handbook. 1 ed. New York: McGraw-Hill. 